\title{
Chromosomal localization, spatio-temporal distribution and polymorphism of the porcine tripartite motif-containing 55 (TRIM55) gene
}

\author{
D.X. Zhang ${ }^{\text {a }}$ K. Li ${ }^{\text {a, b }}$ B. Liu ${ }^{\text {a }}$ Z.M. Zhu ${ }^{\text {b X.W. Xu }}{ }^{\text {a }}$ S.H. Zhao ${ }^{a}$ \\ M. Yerle ${ }^{\text {C }}$ B. Fan ${ }^{\text {a }}$ \\ ${ }^{a}$ Laboratory of Molecular Biology and Animal Breeding, College of Animal Science and Technology, \\ Huazhong Agricultural University, Wuhan; ${ }^{b}$ Department of Gene and Cell Engineering, Institute of Animal Science, \\ Chinese Academy of Agricultural Science, Beijing (P.R. China); \\ ${ }^{\mathrm{c}}$ INRA, Laboratoire de Génétique Cellulaire, Castanet-Tolosan (France)
}

Manuscript received 7 September 2005; accepted in revised form for publication by T. Haaf, 27 October 2005

\section{Rationale and significance}

Tripartite motif-containing 55 (TRIM55) (also known as MURF-2 or RNF29) is a member of the TRIMs family. The TRIM motif is comprised of zinc-binding domains, a RING finger region, a B-box motif and a coiled-coil domain. Among the TRIMs family, TRIM54 (also known as MURF-3 or RNF30), TRIM55 and TRIM63 (also known as MURF-1 or RNF28) are also named muscle-specific RING finger (MURFs) family, a special subgroup of the RING Finger-B box-coiled-coiled (RBCC)/tripartite motif (TRIM) proteins. The three proteins, encoded by distinct genes located on different chromosomes, share a highly conserved N-terminal RING domain and zinc-binding B-box motif as well as two coiled-coil dimerization motif boxes (Centner et al., 2001). The RING-finger which is involved in protein-protein interactions is an unusual type of zinc-binding Cys-His protein

\footnotetext{
Supported by the National Natural Science Foundation of China (30300250) to B. Fan.

Request reprints from B. Fan

Laboratory of Molecular Biology and Animal Breeding

College of Animal Science and Technology

Huazhong Agricultural University

Wuhan 430070 (P.R. China)

telephone: +86-27-87281306; fax: +86-27-87281378

e-mail: fanbin@mail.hzau.edu.cn
}

motif, which has been found in a growing number of proteins and plays roles in signal transduction, ubiquitination, gene transcription, differentiation and morphogenesis (Borden, 1998; Freemont, 2000). In vitro studies suggest that expression of TRIM63 and TRIM54 are required for skeletal myoblast differentiation and myotube fusion (Spencer et al., 2000). Pizon et al. (2002) suggested that TRIM55 proteins acted as cytoskeletal adaptors and signaling molecules by associating with myofibril components (including the giant protein, titin), microtubules and/or nuclear factors. McElhinny et al. (2004) further investigated the function of TRIM55 in primary cultures of embryonic chick skeletal myocytes and demonstrated that TRIM55 antisense oligonucleotides knock-down delayed myoblast fusion, myofibrillogenesis and affected the contractile activity. In this study, we report the physical mapping, preliminary spatio-temporal expression pattern and polymorphism of the porcine TRIM55 gene.

\section{Materials and methods}

Porcine gene-specific primers design

Four alternatively spliced transcript variants of TRIM55 have been identified in human. The longest human TRIM55 cDNA (transcript variant 2, GenBank accession number: NM_033058) was used to search in the 'EST other' database with the standard BLAST (http://www.ncbi. nlm.nih.gov/blast/) algorithm for homologous pig expressed sequence tags (ESTs). The ESTs sharing more than $80 \%$ sequence identity with the human cDNA (NM_033058) were assembled to produce a pig EST-contig. From the EST-contig, two gene-specific polymerase chain reaction (PCR) primer pairs were designed using Primer Premier 5.0 software (http://www.premierbiosoft.com) (Table 1). 
Table 1. Primer pairs used for the analysis of porcine TRIM55 and for $\beta$-actin, a positive control for expression analysis

\begin{tabular}{llll}
\hline Primers & Primer sequence $\left(5^{\prime}-3^{\prime}\right)$ & Size $(\mathrm{bp})$ & Tm $\left({ }^{\circ} \mathrm{C}\right)$ \\
\hline Pair 1 & F: CAAGAATGTGGCACCAGAGTC & 530 & 63 \\
Pair 2 & $\begin{array}{l}\text { R: GCAGCAGGGAACCAAGAT } \\
\text { F: GGAGGCACTATGGTGGGACA }\end{array}$ & 749 & 65 \\
$\beta$-actin & $\begin{array}{l}\text { R: TGCCGATGATGAAAGGGACC } \\
\text { R: GGACTTCGAGCAGGAGATGG }\end{array}$ & 233 & 61 \\
& R: GCACGTGTTGGCGTAGAGG & & \\
\hline
\end{tabular}

Chromosomal localization

The chromosomal localization of the porcine TRIM55 gene was performed using the INRA-University of Minnesota porcine radiation hybrid panel (IMpRH) (Yerle et al., 1998) with primer pair 1. The PCR reactions were performed in 10- $\mu$ l reactions containing $1 \times$ PCR buffer, $0.3 \mu \mathrm{M}$ of each primer, $75 \mu \mathrm{M}$ of each dNTP, $2.0 \mathrm{mM} \mathrm{MgCl}_{2}, 0.5 \mathrm{U}$ Taq DNA polymerase (Promega, Madison, WI, USA ) and $25 \mathrm{ng}$ of hybrid DNA. Amplification protocol was $5 \mathrm{~min}$ at $94^{\circ} \mathrm{C}$, followed by 35 cycles of $40 \mathrm{~s}$ at $94^{\circ} \mathrm{C}, 30 \mathrm{~s}$ at $63^{\circ} \mathrm{C}, 25 \mathrm{~s}$ at $72^{\circ} \mathrm{C}$ and a final extension of 5 min at $72{ }^{\circ} \mathrm{C}$. PCR products were electrophoresed on $2.0 \%$ agarose gel stained with $0.5 \mu \mathrm{g} / \mathrm{ml}$ ethidium bromide. The PCR results obtained on the 118 hybrid clones were analyzed with the IMpRH mapping server (Milan et al., 2000) available on the WWW (http://www.toulouse.inra. fr/lgc/pig/RH/IMpRH.htm).

\section{RT-PCR analysis of pig TRIM55 expression}

The spatio-temporal expression pattern of TRIM55 was investigated using reverse transcriptase-polymerase chain reaction (RT-PCR) with primer pair 2. Total RNAs from porcine tissues were isolated with TRIzol reagent (Invitrogen, Carlsbad, CA, USA) according to the manufacturer's instructions. The five samples collected from 1 day-old Chinese Tongcheng porcine heart, skeletal muscle, spleen, liver, and kidney were used to determine the tissue distribution of the TRIM55 gene. The skeletal muscles sampled from six different stages, i.e., embryos $(30 \mathrm{~d}$, $60 \mathrm{~d}, 90 \mathrm{~d})$ and postnatal pigs ( $1 \mathrm{~d}, 28 \mathrm{~d}$, adult), were used for temporal expression analysis. One microgram RNA was reverse-transcribed with 300 U M-MLV (Promega, Madison, WI, USA). PCR conditions were as follows: $5 \mathrm{~min}$ at $95^{\circ} \mathrm{C}$ followed by 28 cycles of $40 \mathrm{~s}$ at $94^{\circ} \mathrm{C}, 30 \mathrm{~s}$ at $65^{\circ} \mathrm{C}, 30 \mathrm{~s}$ at $72^{\circ} \mathrm{C}$ and a final extension of $5 \mathrm{~min}$ at $72^{\circ} \mathrm{C}$. $\beta$-actin was used as an internal control gene (primer sequences referred from Meadus, 2003).

\section{SNP Identification and PCR-RFLP analysis}

For SNPs scan of the porcine TRIM55, the genomic DNAs of four breeds (Large White, Landrace, Duroc and Tongcheng; two individuals for each breed) were amplified with primer pair 2. The PCR reactions were performed in $20-\mu \mathrm{l}$ reactions with $50 \mathrm{ng}$ of genomic DNA, $0.5 \mu \mathrm{M}$ of each primer, $150 \mu \mathrm{M}$ of each dNTP, $2.0 \mathrm{mM} \mathrm{MgCl}_{2}$ and $2.0 \mathrm{U}$ Taq DNA Polymerase (Promega, Madison, WI, USA) in $1 \times$ PCR buffer. Amplification parameters were the same as described above. The PCR products from Large White and Landrace were mixed (pool 1) and purified with Wizard prep PCR purification system (Promega, Madison, WI, USA) as well as the products from Duroc and Tongcheng (pool 2). Direct sequencing of pool 1 and pool 2 revealed two single nucleotide polymorphisms (SNPs). The A/G transition at position 162 in 3'-untranslated region (3'-UTR) can not be recognized by any restriction endonucleases, while the other single nucleotide mutation $(\mathrm{C} / \mathrm{T})$ at position 213 spans a $B s h 1236$ I restriction site and was further investigated in this paper. Three microliters of PCR products obtained from primer pair 2 were digested overnight with $3 \mathrm{U}$ Bsh1236I (Jingmei Biotech, Shenzhen, China), then size-separated on an ethidium bromide stained 2.0\% agarose gel in $1 \times$ TAE buffer. In total 126 DNA samples of unrelated animals from five different pig breeds (Large White, Landrace, Duroc, Tongcheng and Erhualian) were genotyped by PCR-restriction fragment length polymorphism (RFLP) technique.

\section{Results}

\section{Chromosomal localization using PCR-based hybrid mapping}

According to the BLAST result, five partially overlapping porcine ESTs (GenBank accession number: DN123590, CK449701, DN123925, DN110610 and CF795586) were searched and assembled to produce a pig EST-contig. Two primer pairs based on the contig yielded two overlapping PCR fragments, $530 \mathrm{bp}$ (DQ160212) and $749 \mathrm{bp}$ (DQ160211), respectively. The sequences DQ160212 and DQ160211 located in the 3'-UTR of porcine TRIM55 matched the human cDNA sequence (NM_033058) with the identities 78-82\% and $79-95 \%$, respectively.

Using the INRA IMpRH panel and primer pair 1, TRIM55 was assigned close to SW1475 (LOD score value 9.74, distance $42 \mathrm{cR}$ ) on chromosome 4 (SSC4). The other three microsatellite markers linked with TRIM55 were SW839 $(\mathrm{LOD}=8.53,46 \mathrm{cR}), \mathrm{SW} 742(\mathrm{LOD}=7.21,54 \mathrm{cR})$ and $\mathrm{SW} 1073(\mathrm{LOD}=6.2,64 \mathrm{cR}$ ) respectively. The retention frequency was $23 \%$. SW 839 had been exactly mapped to $4 \mathrm{q} 11$ $\rightarrow$ q14 in the previous study (Hawken et al., 1999), so the most probable chromosomal localization for TRIM55 is SSC4q11 $\rightarrow \mathrm{q} 14$.

\section{Spatio-temporal expression pattern of TRIM55}

The RT-PCR results revealed that porcine TRIM55 expression was restricted to heart and skeletal muscle; although a low level of transcripts was detected in spleen (Fig. 1a). Meanwhile, TRIM55 expression levels were found to be upregulated in pig skeletal muscle during the embryo stages and down-regulated during the pig postnatal development (Fig. 1b).

\section{Identification of genetic polymorphism}

SNPs were scanned in the fragment obtained from primer pair 2 and a polymorphic restriction site was detected with $B s h 1236$ I. The digested products displayed allelic fragments of $749 \mathrm{bp}$ (allele T) or $537+212 \mathrm{bp}$ (allele C) (Fig. 2). This $\mathrm{C} / \mathrm{T}$ variation was further analyzed in five pig breeds. The sample size and allele frequencies of each breed are given in Table 2. The allele distribution revealed that the Chinese indigenous breeds have a predominant frequency of allele $\mathrm{C}$. 
Fig. 1. The spatio-temporal expression pattern of porcine TRIM55. (a) RT-PCR tissue distribution of TRIM55 in heart, skeletal muscle, spleen, liver and kidney. (b) Temporal expression analysis of TRIM55 in skeletal muscle. Embryonic: 30 d, 60 d, 90 d embryo respectively; Postnatal: $1 \mathrm{~d}, 28 \mathrm{~d}$, adult (age at $90 \mathrm{~kg}$ ) respectively. $\beta$-actin is a positive control; $\mathrm{N}$ : negative control; M: 1000-100 bp marker.

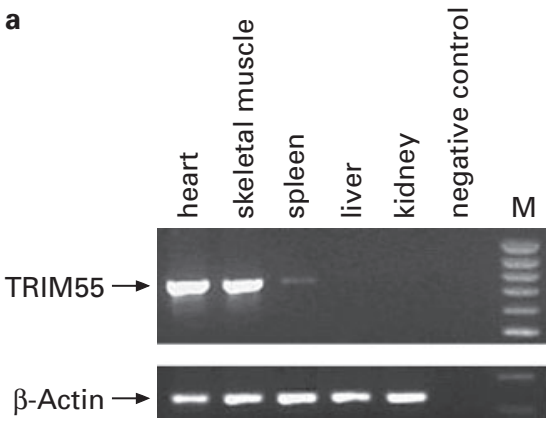

b

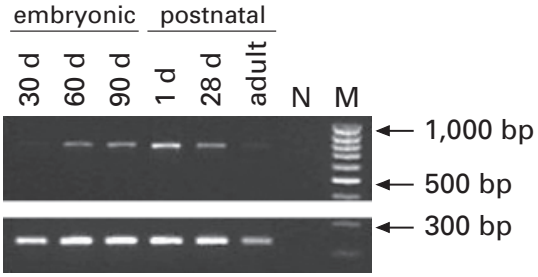

Fig. 2. Bsh1236I PCR-RFLP genotyping of porcine TRIM55 (M: 1000-100 bp marker.)

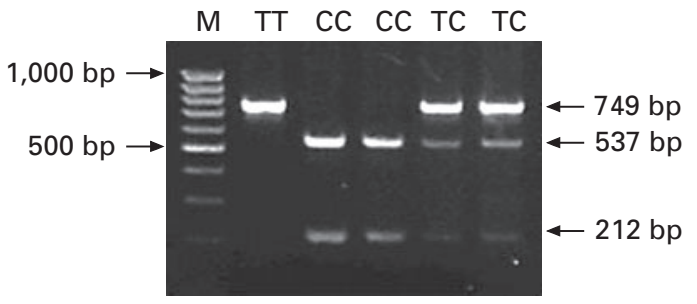

Table 2. Genotypes and allele frequencies of Bsh1236I-RFLP for the TRIM55 gene in five pig breeds

\begin{tabular}{|c|c|c|c|c|c|c|}
\hline \multirow[t]{2}{*}{ Breeds } & \multirow{2}{*}{$\begin{array}{l}\text { Sample } \\
\text { size }\end{array}$} & \multicolumn{3}{|c|}{ Genotype } & \multicolumn{2}{|c|}{ Allele frequency } \\
\hline & & TT & $\mathrm{TC}$ & $\mathrm{CC}$ & $\mathrm{T}$ & $\mathrm{C}$ \\
\hline Large White & 25 & 3 & 8 & 14 & 0.2800 & 0.7200 \\
\hline Landrace & 26 & 9 & 16 & 1 & 0.6538 & 0.3462 \\
\hline Duroc & 19 & 0 & 15 & 4 & 0.3947 & 0.6053 \\
\hline Tongcheng & 38 & 0 & 0 & 38 & 0 & 1 \\
\hline Erhualian & 18 & 0 & 0 & 18 & 0 & 1 \\
\hline
\end{tabular}

\section{Discussion}

In human, TRIM55 has been localized on chromosome $8 \mathrm{q} 12 \rightarrow \mathrm{q} 13$ by radiation hybrid mapping (Centner et al., 2001). In this study, the porcine TRIM55 gene was assigned to SSC4q11 $\rightarrow$ q14, which is in good agreement with the human-pig comparative maps as porcine chromosome $4 \mathrm{q} 11 \rightarrow$ q14 has been shown to share homology with human chromosome 8q (HSA8q) (http://www.toulouse.inra.fr/lgc/pig/compare/SSCHTML/SSC4S.HTM). According to the spatio-temporal expression pattern of TRIM55, we suggest that TRIM55 is developmentally regulated and probably plays a crucial role during the embryo and early postnatal skeletal development stages. In human and mouse, the similar expression patterns of TRIM55 were also observed (Centner et al., 2001; McElhinny et al., 2004).
The efficient function of striated muscle is dependent on the precise interactions and alignment of complex cytoskeletal networks. In vitro studies showed that TRIM55 associated transiently with microtubules, myosin filaments and titin during sarcomere assembly as well as being involved in signaling from the sarcomere to the nucleus (Pizon et al., 2002). Therefore TRIM55 was proposed to be a molecule shuttle to link these cytoskeletal arrays during muscle development, and might affect the expression or activity of other genes in muscle (McElhinny et al., 2004). In this study, porcine TRIM55 was mapped to chromosome 4 (SSC4) where many significant quantitative trait loci (QTL) affecting growth, muscle, fat deposition, carcass and backfat thickness have been identified (Varona et al., 2002; Cepica et al., 2003; Geldermann et al., 2003; Moller et al., 2004). According to the expression pattern analysis results, it can be deduced that TRIM55 is important for normal muscle development. Taken together, these data show that TRIM55 is a valuable candidate gene for traits related to skeletal muscle development and meriting further investigation. 


\section{References}

Borden KL: RING finger and B-boxes: zinc-binding protein-protein inteaction domains. Biochem Cell Biol 76:351-358 (1998).

Centner T, Yano J, Kimura E, McElhinny AS, Pelin K, Witt CC, Bang ML, Trombitas K, Granzier H, Gregorio CC, Sorimachi H, Labeit S: Identification of muscle specific ring finger proteins as potential regulators of the titin kinase domain. J Mol Biol 4:717-726 (2001).

Cepica S, Stratil A, Kopecny M, Blazkova P, Schröffel J Jr, Davoli R, Fontanesi L, Reiner G, Barten-schlager H, Moser G, Geldermann H: Linkage and QTL mapping for Sus scrofa chromosome 4. J Anim Breed Genet 120:28-37 (2003).

Freemont PS: RING for destruction? Curr Biol 10:R84-87 (2000).

Geldermann H, Müller E, Moser G, Reiner G, Bartenschlager H, Cepica S, Stratil A, Kuryl J, Moran C, Davoli R, Brunsch C: Genome-wide linkage and QTL mapping in porcine F2 families generated from Pietrain, Meishan and Wild Boar crosses. J Anim Breed Genet 120:363-393 (2003).

Hawken RJ, Murtaugh J, Flickinger GH, Yerle M, Robic A, Milan D, Gellin J, Beattie CW, Schook LB, Alexander LJ: A first-generation porcine whole-genome radiation hybrid map. Mamm Genome 10:824-830 (1999).

McElhinny AS, Perry CN, Witt CC, Labeit S, Gregorio CC: Muscle-specific RING finger-2 (MURF-2) is important for microtubule, intermediate filament and sarcomeric M-line maintenance in striated muscle development. J Cell Sci 117:3175-3188 (2004).

Meadus WJ: A semi-quantitative RT-PCR method to measure the in vivo effect of dietary conjugated linoleic acid on porcine muscle PPAR gene expression. Biol Proced Online 5:20-28 (2003).
Milan D, Hawken R, Cabau C, Leroux S, Genet C, Lahbib Y, Tosser G, Robic A, Hatey F, Alexander L, Beattie C, Schook L, Yerle M, Gellin J: IMpRH server: an RH mapping server available on the web. Bioinformatics 16:558-559 (2000).

Moller M, Berg F, Riquet J, Pomp D, Archibald A, Anderson S, Feve K, Zhang Y, Rothschild M, Milan D, Andersson L, Tuggle CK: High-resolution comparative mapping of pig Chromosome 4, emphasizing the FAT1 region. Mamm Genome 15:717-731 (2004)

Pizon V, Iakovenko A, Van Der Ven PF, Kelly R, Fatu C, Furst DO, Karsenti E, Gautel M: Transient association of titin and myosin with microtubules in nascent myofibrils directed by the MURF2 RING-finger protein. J Cell Sci 115:4469-4482 (2002).

Spencer JA, Eliazer S, Ilaria RL Jr, Richardson JA, Olson EN: Regulation of microtubule dynamics and myogenic differentiation by MURF, a striated muscle RING-finger protein. J Cell Biol 150:771-784 (2000).

Varona L, Ovilo C, Clop A, Noguera JL, Perez-Enciso M, Coll A, Folch JM, Barragan $\mathrm{C}$, Toro MA, Babot D, Sanchez A: QTL mapping for growth and carcass traits in an Iberian by Landrace pig intercross: additive, dominant and epistatic effects. Genet Res 80:145-154 (2002).

Yerle M, Pinton P, Robic A, Alfonso A, Palvadeau Y, Delcros C, Hawken R, Alexander L, Beattie C, Schook L, Milan D, Gellin J: Construction of a wholegenome radiation hybrid panel for high-resolution gene mapping in pigs. $\mathrm{Cy}-$ togenet Cell Genet 82:182-188 (1998). 